\title{
Atividade criadora em momento de pandemia: relato de experiência das aulas de
}

\section{língua inglesa}

\author{
Creating activity in pandemic moment: experience report of english language classes
}

\section{Daniela Aparecida Vendramini-Zanella}

Universidade de Sorocaba - UNISO - São Paulo - Brasil

\section{Beatriz Oliveira Delboní}

Universidade de Sorocaba - UNISO - São Paulo - Brasil

\begin{abstract}
Resumo: Este texto tem por objetivo relatar a experiência de uma professorapesquisadora nas aulas de língua inglesa em uma universidade, com transposição didática em momento de pandemia. Para tal, descreve-se a proposta de ensinoaprendizagem por meio da Atividade Social: "interview" e se analisa um questionário respondido pelos discentes. Com base na metodologia de pesquisa qualitativa com ênfase no paradigma crítico, a análise dos comentários tecidos pelos alunos centraliza os aspectos enunciativo-discursivo-linguísticos e são interpretados mediante o aporte teórico apresentado. Constatou-se que a proposta de ensino-aprendizagem de língua inglesa por meio da Atividade Social: "interview" configura-se como uma transposição didática com indícios de atividade criadora por apresentar recombinações, possibilitar o desenvolvimento dos alunos e criar algo novo em momento de pandemia.
\end{abstract}

Palavras-chave: Atividade criadora. Ensino-aprendizagem. Língua Inglesa. Transposição didática.

\begin{abstract}
This text aims to report the researcher-teacher experience on English language classes in a university dealing with didactic transposition in pandemic moment. For this purpose, it describes the teaching learning proposal through the Social Activity: "interview" and analyses a questionnaire answered by students. Grounded in the qualitative research methodology with emphasis in the critical paradigm, the analysis of students' comments centralizes the enunciative-discursivelinguistic aspects and is interpreted through the theoretical contribution presented. The data showed that the English language teaching learning proposal through the Social Activity: "interview" configures a didactic transposition with creating activity's evidence because it presents recombination, it offers the possibility to student's development and it creates something new in pandemic moment.
\end{abstract}

Keywords: Creating activity. Teaching-learning. English language. Didactic transposition. 


\section{Introdução}

Quem se imaginou vivenciar uma pandemia? O que parecia ficção, tornou-se realidade; trancados em casa, sem poder lecionar em salas de aula com alunos e sequer estar presencialmente no campus. Eis que no início do mês de março deste ano de 2020, o cenário nacional enfrentou a notícia de disseminação da contaminação do coronavírus (SARS-CoV-2), causador da Covid-191, que se espalhava em diferentes continentes do mundo e, inclusive, por vários estados brasileiros. Em meio aos boletins de números de infectados e descrições de ações preventivas, aconselhava-se o distanciamento social. Diante disso, o governo estadual de São Paulo decretou que as atividades em contexto escolar fossem suspensas a partir do dia 23 de março. Com essa notícia, muitas universidades já decidiram cancelar os encontros presenciais e a inquietação surgiu: como dar continuidade às atividades?

Em situação de isolamento social e preocupada com a manutenção do processo recém iniciado, a professora-pesquisadora deparou-se com a necessidade de repensar as práticas de ensinoaprendizagem, agora mediadas por ferramentas virtuais. Apresentava pouca experiência em lecionar pelo modo virtual, pois havia apenas utilizado a plataforma oficial da universidade para medição de ensino à distância.

Então, a transposição didática tornou-se a alternativa para atender as demandas do novo cenário. Segundo Garonce e Santos (2012, p. 1006), a discussão sobre transposição didática origina-se com o educador francês Chevallard (1985) e pode ser compreendida como uma nova forma de relação didática que repaginou uma abordagem conhecida por "ensinante ensinado", integrando "o saber" na relação, em que docentes, alunos e saberes compõem o sistema didático. Neste texto, pode-se expandir a noção de transposição didática para a necessidade de transformação do saber e adequação do conhecimento que deveria ser levado para sala de aula, diante a mudança do presencial para o não- presencial como forma de se conter a disseminação da COVID-19.

Ainda, no papel de educadora, a professorapesquisadora teria que conduzir as aulas de forma equilibrada, esquivando-se do desespero e considerando as dificuldades e restrições da realidade do aluno. Dessa forma, constatou a necessidade de redesenhar as principais tarefas em língua estrangeira que se apresentam como essenciais à formação profissional dos discentes, antes realizadas na modalidade presencial e agora repensadas no virtual.

No curso de Comércio Exterior, por exemplo, os alunos precisam desenvolver competências nas quatro habilidades da língua inglesa, que os possibilitem a participar das atividades na esfera de negócios ligada à exportação e à importação, como: escrever e responder uma mensagem, solicitar um orçamento, apresentar resultados de vendas em uma reunião com leitura e interpretação de gráficos, participar de uma entrevista para vaga de emprego (GOMES,1998), entre outras.

Nessa direção, lançou-se o desafio de desenvolver o ensino-aprendizagem que articule teoria e prática e considere os contextos dos alunos permeados por emoções, restrições, necessidades e, a partir da compreensão dessas realidades, propicie transformações. Por isso, este texto fundamenta-se teórico-metodologicamente na perspectiva sóciohistórico-cultural (VYGOTSKY, 1934/2001). Dentro desse arcabouço, elege-se a organização curricular por meio de Atividade Social² (LIBERALI, 2009) e o conceito do brincar/performance como base para se pensar a realidade em vias de desenvolvimento, integrando-se a e conduzindo novas propostas de ensino-aprendizagem que promovam a reflexão e a compreensão da realidade dos alunos para que possam problematizá-las e transformá-las de forma crítica.

Dessa forma, a professora-pesquisadora inseriu-se em fase de revisitar suas práticas, recombinar o que já realizava e modificar sua atuação elaborando a proposta de ensino-aprendizagem de língua inglesa por meio da Atividade Social (AS 
doravante): 'interview' (entrevista em língua inglesa), agora na modalidade virtual, em curso de Comércio Exterior. Em uma visão vygotskyana, essa criação e recriação das práticas docentes com transposição didática relaciona-se com a práxis criadora, compreendida como uma produção que inclui a dialética - entre as categorias gerais da cultura - e as experiências materiais e emocionais com as quais os sujeitos interagem quando trazem algo novo ao significado por meio dos sentidos (MORAN; JOHNSTEINER, 2003). Assim, pode-se dizer que a transposição didática se configura como uma atividade criadora e o brincar é responsável por essa realização.

Ainda sob a perspectiva sócio-históricocultural, em que o brincar é elemento essencial para o desenvolvimento humano (VYGOTSKY, 1930/2009), a atividade é concebida como a unidade da vida que orienta o sujeito no mundo dos objetos por meio de instrumentos; construídos pelo homem para produzir os meios de satisfazer suas necessidades vitais (LEONTIEV, 1977). Necessidade, objeto e motivo incluem os componentes estruturais da atividade.

Por isso, acredita-se que o brincar em proposta de ensino-aprendizagem, por possibilitar ao aluno planejar, imaginar situações e representar papéis além de si mesmo (HOLZMAN, 2009), pode propiciar o desenvolvimento do aluno na apropriação da língua inglesa, instigando-o a refletir sobre a importância de sua formação acadêmica e profissional, mesmo em tempo de pandemia, quando surgem incertezas e desconfortos; assegurando-o a permanência no seu processo e ultrapassando as restrições estabelecidas pela realidade imediata. Essa manutenção do aluno em seu processo de formação no Curso de Comércio Exterior apresentou-se como central para que a professora-pesquisadora iniciasse sua possível práxis criadora, conforme será relatado.

Este texto tem por objetivo relatar a experiência de uma professora-pesquisadora nas aulas de língua inglesa na universidade com transposição didática em momento de pandemia. Organiza-se a, em primeiro lugar, introduzir a perspectiva sócio-histórica-cultural e, ligada a ela, os conceitos de atividade criadora, do brincar/performance e de organizador curricular por meio de AS. Essa seção finaliza-se com a descrição da proposta de ensino-aprendizagem por meio da AS: 'interview'. Por segundo, apresentar a metodologia de pesquisa pautada na pesquisa qualitativa com ênfase no paradigma crítico, descrevendo-se o contexto de intervenção e os procedimentos de produção e análise de dados. $\mathrm{Na}$ sequência, os dados são analisados pelos aspectos enunciativo-discursivolinguísticos (LIBERALI, 2013) e interpretados mediante o aporte teórico apresentado. Por último, apresentam-se as considerações finais.

2 Perspectiva sócio-histórica-cultural: a atividade criadora, as propostas de ensinoaprendizagem por meio de AS e o brincar

A perspectiva sócio-histórico-cultural foi formulada por Vygotsky (1934/2001) e, posteriormente, expandida por Leontiev (1977) e Engeström (1999), e abrange que os sujeitos, historicamente, constituem a si mesmos e aos demais por meio de relações que são mediadas socialmente (VENDRAMINI-ZANELLA; LIBERALI, 2011, p. 96).

É visível a influência do legado de Karl Marx (1818-1883)3 na perspectiva em questão, enraizada no materialismo histórico-dialético; portanto, possui como referência a filosofia marxista de que não basta descrever o mundo, mas que se faz necessário agir a fim de modificá-lo (LEFFA, 2011, p. 29). Além disso, sabe-se que, para Marx, o trabalho é a atividade em que o homem cria a si mesmo, constitui-se como sujeito; desse modo, a atividade humana é como ele irá agir no mundo, pois pode, por meio do desenvolvimento de sua produção material e relações materiais, alterar sua realidade e criar sua história, ou seja, pensar na "vida que se vive" (MARX; ENGELS, 1845-46/2006, p. 26).

Nessa direção, assume-se a perspectiva sócio-histórico-cultural como alternativa para melhor desenvolvimento dos alunos nas aulas de língua inglesa, porque considera que sujeito e mundo são 
tratados conjuntamente. Dessa forma, o sujeito age e reflete sobre suas ações e seus contextos, tendo a possibilidade de criar, produzir conhecimento e transformar o mundo (LIBERALI, 2009, p. 10). Então, ao se deparar com a situação da pandemia e vislumbrando a transposição didática como alternativa para que o processo tivesse continuidade, a professora-pesquisadora revisitou suas práticas, recombinou o que já realizava e modificou sua atuação, elaborando a proposta de ensinoaprendizagem de língua inglesa por meio da AS: 'interview', agora na modalidade virtual, em curso de Comércio Exterior.

Essa recombinação, modificação, criação e recriação das práticas docentes na transposição didática, analisadas em perspectiva vygotskyana, relacionam-se com a práxis criadora, compreendida como uma produção que inclui a dialética - entre as categorias gerais da cultura - e as experiências materiais e emocionais com as quais os sujeitos interagem quando trazem algo novo ao significado por meio dos sentidos (VYGOTSKY, 1934, apud VENDRAMINI-ZANELLA, 2013, p.49).

Sánchez-Vázquez (2011, p. 269) explica que a práxis criadora permite enfrentar novas necessidades e novas situações. O autor adiciona que, embora esse processo criador não seja um estado constante - uma vez que a práxis se caracteriza "por um ritmo alternado do criador e do imitativo, da inovação e da reiteração" - a cada nova necessidade ou situação, os sujeitos criam. Marx e Engels (1845-46/2006) apontam que a necessidade essencial dos seres humanos é criar, porque só criando e transformando o mundo, criam-se a si mesmos e a um mundo humano. Com base nessa visão marxista, SánchezVázquez (2011) formula os seguintes traços da atividade criadora: indissociabilidade do subjetivo e do objetivo no processo prático; imprevisibilidade do processo e do resultado e unidade e irrepetibilidade do produto (VENDRAMINI-ZANELLA, 2013, p. 49).

Essa visão é fundamental para as práticas docentes uma vez que a atividade criadora configurase de duas formas na perspectiva de Vygotsky (1930/2009): a 'reprodutiva', em que reconstitui algo, e a 'criadora', em que se combina (VENDRAMINIZANELLA, 2018, p. 161), ainda mais focadas em situação de enfrentamento de uma pandemia em que surge a necessidade de se propor uma transposição didática. Ambas as visões de atividade criadora possibilitam a criação de algo novo, sendo que a 'reprodutiva' pode estar ligada à conservação das experiências anteriores, à repetição de hábitos permanentes e de condutas já formadas e criadas anteriormente. Adicionalmente, a lei fundamental a que se subordina a atividade da imaginação é a de que,

a atividade criadora da imaginação
depende diretamente da riqueza e da
diversidade da experiência anterior da
pessoa, porque essa experiência
constitui o material com que se criam
as construções da fantasia. Quanto
mais rica a experiência da pessoa,
mais material está disponível para a
imaginação dela (VYGOTSKY,
1930/2009, p. 22).

Nessa esteira vygotskyana, em que a experiência ligada à imaginação potencializa a atividade criadora, coloca-se em relevo a importância das emoções compartilhadas na atividade, da produção de sentidos e maneiras de como essa experiência pode proporcionar comprometimento, vontade e personalidade criativa (MORAN; JOHNSTEINER, 2003).

Relacionada à atividade criadora, portanto, a transposição didática, aqui discutida, pauta-se na proposta de ensino-aprendizagem de língua inglesa por meio de AS visando promover a participação e permanência dos sujeitos em seus processos em momento de pandemia.

Conforme proposto por Leontiev (1977) e Engeström (1999), uma Atividade é mediada por meio da linguagem e composta por diferentes itens que são articulados dentro de uma perspectiva sócio-históricocultural. Uma AS é constituída por sujeitos que percebem suas necessidades e que são motivados por um propósito: o objeto desejado. Esse processo será mediado por artefatos/instrumentos por meio de uma relação entre a comunidade, constituída a partir de regras e marcada por uma divisão de trabalho. 
Assim, toda atividade é impulsionada por uma necessidade em constante transformação.

Integrando-se uma AS ao processo de ensinoaprendizagem, prioriza-se o uso de artefatos culturais, pois irão colaborar para a transformação dos sujeitos envolvidos na sequência da atividade (PHILIPPOV; LIBERALI, 2015, p. 75). É possível empregar os artefatos culturais nas diferentes práticas discursivas, como a utilização de músicas, vídeos, livros, jornais, entre outros.

Ainda, o componente de artefatos ou instrumentos em uma proposta de ensinoaprendizagem por meio de AS torna-se essencial para se alcançar o resultado esperado. Faz-se importante relacionar a linguagem na atividade com o conceito de instrumento-e-resultado, em que "o método é simultaneamente pré-requisito e produto" (VYGOTSKY,1934/2001 apud NEWMAN; HOLZMAN, 1993/2002, p. 47). Neste estudo, por exemplo, a língua inglesa pode ser considerada como instrumento-e-resultado e não somente como o objeto a ser alcançado.

Também, empresta-se a noção dos gêneros da filosofia da linguagem, para o âmbito educacional em que se considera os gêneros como megainstrumentos (DOLZ; SCHNEUWLY, 2004) da atividade. Por último, vale ressaltar que, o ensinoaprendizagem dentro da organização curricular por meio de AS torna-se relevante por estar intrinsecamente relacionada à "vida que se vive" (MARX; ENGELS, 1845-46/ 2006, p. 26), enfatizando "o conjunto de ações mobilizadas por um grupo para alcançar um determinado motivo/ objetivo, satisfazendo necessidades dos sujeitos" (LIBERALI, 2009, p. 11).

Quando se fala em propostas de ensinoaprendizagem por meio de AS, faz-se necessário apresentar o conceito do brincar na perspectiva sóciohistórico-cultural. Nele, estão inseridos os jogos, a imaginação, a fantasia, o faz-de-conta, a encenação, o prazer e também o divertimento. Conforme Holzman (2009), consideram-se três tipos: o brincar livre, o brincar regrado e a performance, que pode ser tanto livre quanto com script (VENDRAMINIZANELLA; LIBERALI, 2011, p. 97).

Compreendida no brincar, a performance é utilizada na criação de situações que expressam desejos, pensamentos e ambições que ainda estão no plano imaginário (HOLZMAN, 2009). Por essa interligação conceitual, em viés vygotskyano, decidese por se utilizar o sintagma brincar/performance neste texto. Através do brincar/performance proporciona-se um momento de reflexão ao aluno. No estudo de Vendramini-Zanella e Liberali (2011), por exemplo, as crianças desenvolvem uma performance tomando como base a AS "brincar de ir à piscina e nadar", que é realizada no corredor de um hospital infantil. Por estarem em contexto hospitalar, nesse caso, ir à piscina e, até mesmo brincar com água, eram provavelmente apenas sonhos para aquelas crianças que estavam em tratamento (DELBONI; VENDRAMINI-ZANELLA, 2019, p. 259).

O conceito de atividade criadora do homem, anteriormente abordado, está relacionado ao brincar, pois a partir das experiências que são proporcionadas pelas brincadeiras, desperta-se a imaginação e a fantasia, colaborando para desenvolvimento do sujeito e, consequentemente, o desenvolvimento do seu futuro, além de transformar sua realidade e poder modificar o seu presente; processo que ocorrerá de forma criativa.

Dessa forma, o brincar proporciona experiências que vão além das possibilidades imediatas e contribui para que os alunos percebam outras formas de atuação no mundo (LIBERALI, 2009, p. 19); potencializa-se a realização desta atividade criadora. Portanto, neste estudo, pressupõem-se o trabalho com base em uma proposta de ensino-aprendizagem por meio de AS e o brincar como possibilidade de se enfrentar o momento de pandemia, visando o desenvolvimento dos alunos.

Antes de se descrever a proposta de ensinoaprendizagem de língua inglesa por meio da AS: "interview", faz-se importante sintetizar, conforme exposto por Vendramini-Zanella (2013), alguns pontos que devem ser definidos para a organização 
curricular, a saber: as perspectivas de ensinoaprendizagem, a concepção de linguagem, o ensinoaprendizagem de língua estrangeira no currículo, o motivo e os objetos trabalhados a satisfazer necessidades dos sujeitos na "vida que se vive" (MARX; ENGELS, 1845-46/2006) e os gêneros como megainstrumentos (DOLZ; SCHNEUWLY, 2004) na atividade em foco. No caso da proposta por meio de AS: "interview" discutida neste estudo, considerou-se a perspectiva sócio-histórica-cultural de ensinoaprendizagem e a concepção dialógica de linguagem (BAKHTIN/VOLOCHINOV, 1929/2010) e os gêneros: cover letter, résumé e interview, por exemplo.

Descreve-se os componentes proposta de ensino-aprendizagem de língua inglesa por meio da AS: 'interview', com base na descrição proposta por Engeström (1999) e comentada por Liberali (2009): sujeitos: candidato à vaga, que são os alunos de Comércio Exterior e o profissional de recursos humanos (ou da área de Comércio Exterior); divisão de trabalho: candidatos - elaboram cover letter, résumé e se preparam para a entrevista em língua inglesa o profissional lê cover letter e résumé dos candidatos, os entrevistados; objeto: participar de uma entrevista de emprego em língua inglesa, denominada 'interview'; regras: os candidatos devem se candidatar à vaga; enviar, previamente, résumé (currículo em língua inglesa) e cover letter (carta de apresentação em língua inglesa) e participar da entrevista (seguindo as especificidades dos gêneros). O profissional deve receber o candidato e entrevistar. E, por último, artefatos: gêneros (résumé, cover letter e a própria "interview") que se configura como instrumento-e-objeto (NEWMAN; HOLZMAN, 1993/2002), computador, cadeiras, mesa, blogs com as principais perguntas para uma entrevista de emprego, entre outros.

\section{Procedimentos metodológicos e procedimento de análise}

Este artigo tem por objetivo relatar a experiência de uma professora-pesquisadora nas aulas de língua inglesa na universidade com transposição didática em momento de pandemia. Apresenta como metodologia a pesquisa qualitativa com ênfase no paradigma crítico (MINAYO, 1993). Esse paradigma embasa-se nas discussões de Paulo Freire (1987) e nas expansões de Henry Giroux (1999), e considera o campo dos significados, dos motivos, das aspirações, das crenças, dos valores e das atitudes como caminho científico que não podem ser reduzidos à uma instrumentalização de dados e variáveis.

Ao enfoque qualitativo e crítico deste estudo, adicionou-se dados quantitativos advindos de um questionário; respondido com vinte e cinco alunos do quinto semestre de Comércio Exterior, de uma turma de trinta e quatro alunos. A razão pela qual nem todos os alunos responderam ao questionário não foi investigada. Sabe-se que questões como transposição didática não se constata por meio de dados quantitativos, os quais, neste estudo, foram utilizados de forma dialogal com os comentários de alunos na tentativa de se tecer reflexões, discutir possibilidades e, talvez, colaborar no apontamento de indícios de a proposta de ensino-aprendizagem se configurar como atividade criadora, promotora da manutenção do processo de ensino-aprendizagem em tempo de pandemia. Para a produção, coleta, organização e armazenamento dos dados foram seguidos os princípios éticos da universidade no Comitê de Ética da Universidade de XXX https://www./ acessado em Maio de 2016, CAAE: xxxxxxxx (03/08/2016).

Conforme Lima (2008), o questionário organiza-se a elaborar e aplicar perguntas e alternativas de respostas ligadas ao que está sendo investigado na pesquisa. As perguntas do tipo aberta possibilitam que o aluno coloque sua opinião de forma livre, enquanto, a de tipo fechada oferece duas alternativas como respostas, o que possibilita se alcançar dados mais precisos, de caráter qualitativo. Já a de múltipla escolha é fechada, apresentando várias alternativas de respostas previamente elaboradas. Neste estudo, adota-se o questionário com seis perguntas de múltipla escolha e campos para comentários dos alunos sobre a proposta de 
ensino-aprendizagem por meio da AS: 'interview'. A análise dos comentários centraliza os aspectos enunciativo-discursivo-linguísticos (LIBERALI, 2013) e são interpretados mediante 0 aporte teórico apresentado.

Entre esses aspectos enunciativos, identificamos o local e o momento de produção, recepção e circulação das experiências, bem como o papel social dos envolvidos na produção dessas. Em relação às questões discursivas, analisamos os "tipos de argumentos" que são introduzidos nos enunciados dos alunos-professores ao apresentarem uma elaboração caracterizada pela intenção em estabelecer um contrato com o outro na tentativa de sustentar seu ponto de vista (PERELMAN; OLBRECHTS- TYTECA, 1958/2005). Para maior entendimento desse conceito, coloca-se o tipo de argumento de exemplo' em que se menciona um fato ou caso anterior, para confirmar a ideia que se está sustentando. Adicionalmente, podem utilizar 'tipo de argumento de explicação', 'adversativa', e 'de ilustração'. Finalmente, quanto às questões linguísticas e operadores argumentativos (por exemplo: mas, porém), conectando-as aos conceitos discutidos na revisão da literatura. Por último ainda sobre a análise, os nomes dos alunos que aparecem no recorte são substituídos por suas iniciais.

\section{Descrição do contexto de produção}

Este estudo situa-se no contexto de aulas de língua inglesa em curso de graduação bacharelado em uma universidade comunitária do interior do estado de São Paulo em que os alunos participam de uma proposta de ensino-aprendizagem por meio de AS: 'interview'. O curso é constituído por oito semestres e a língua inglesa é componente curricular do quinto semestre, momento em que os alunos já estão estagiando na área profissional e participando de entrevistas de emprego.

Deve-se ressaltar que, situados em momento de pandemia, muitos alunos demonstraram dificuldades em se manter no processo. Alguns apresentaram resistência ao ensino em modalidade virtual, além de restrições para continuarem participando por conta da qualidade de seus dispositivos e conexão de internet; surgiram até mesmo questões emocionais ligadas ao fato de sentirem falta do tipo de interação social promovida em modalidade presencial, lacuna na concentração para permanecer muito tempo na frente do computador e responder a demanda de um novo formato de aprendizagem que requer a autonomia do aluno.

A professora-pesquisadora do componente curricular de língua inglesa integra-se à área de Linguística Aplicada e, neste estudo, o foco recai na reflexão sobre a ação junto a seu grupo de pesquisa inscrito no Diretório do CNPq, intitulado "xxx", (2015 atual, $x x x$ espelhogrupo/xx) da Universidade XX. Este grupo é constituído por professores-pesquisadores, alunos-professores do curso de Letras Português/Inglês (bolsistas do Programa de Extensão universitária e do Programa de Iniciação CientíficaCNPq).

Por último, é importante ressaltar que a produção de dados ocorreu após as seguintes etapas da atividade: 1- apresentação da proposta, inicialmente, realizada na modalidade presencial e, na sequência, passou por mudanças, configurando-se por uma transposição didática e seguiu em modalidade virtual; 2- produção, correção e avaliação da elaboração dos gêneros da esfera profissional: résumé e cover letter; 3- explicação e negociação sobre a produção do gênero (que, neste estudo, apresenta-se como instrumento-e-resultado): "interview". 4- finalmente, realização da brincadeira/performance: "interview", como tarefa avaliativa individual, por meio de vídeo chamada via aplicativo virtual. Todos os alunos da sala participaram.

\section{Discussão dos dados}

O questionário, realizado com os 35 alunos da turma, apresenta seis perguntas de múltipla escolha com um campo para que pudessem, opcionalmente, inserir comentários. Aponta-se que são enunciados 
de alunos de graduação em curso de Comércio Exterior, em quinto semestre, alguns já inseridos na esfera profissional - de negócios - por meio de estágio e, outros ainda em busca de uma oportunidade. $O$ momento de produção de dados desses alunos estabelece-se nas aulas de língua inglesa em que a professora trabalha a proposta de ensinoaprendizagem de língua inglesa por meio da AS: "interview". A atividade ocorre em etapas e a produção final se realiza em uma entrevista individual entre aluno e professora-pesquisadora por meio de aplicativo virtual.

Mesmo diante restrições e dificuldades geradas pelo momento de pandemia, espera-se um aluno participativo e interessado no alcance do objetivo da proposta de ensino-aprendizagem que envolve questões da língua inglesa e práticas de linguagem ligadas ao gênero entrevista de emprego. Já o papel social do aluno durante a entrevista alterase para candidato a uma vaga de emprego. Por último, a professora-pesquisadora executa o papel de mediadora e condutora da proposta de ensinoaprendizagem por meio de AS como transposição didática, visando a continuidade do processo em momento de pandemia, lidando, ainda, com as dificuldades e as questões emocionais dos alunos que acabam vindo à superfície. Finalmente, a professora-pesquisadora, durante a entrevista, assume o papel de profissional na área de negócios.

Das respostas obtidas no questionário, a primeira questão aponta que $92 \%$ dos participantes acharam que, ao apresentar o tópico "Interview", a professora-pesquisadora disponibilizou, na Plataforma virtual (Moodle), artefatos como exemplos, modelos, vídeos explicativos em língua inglesa (para serem acompanhados) e textos (links de blogs) sobre interview/résumé e cover letter de forma excelente para a compreensão e execução da atividade e, 4\% responderam boa e outros $4 \%$ satisfatório (pergunta 1).

Nesta primeira questão, tem-se os seguintes comentários:

G: "Nos ajudou a entender como fazer e nos comportar nessas ocasiões, foi ótimo. (ponto de vista).

\begin{abstract}
M: "Achei de suma importância todo o material disponibilizado pela professora (ponto de vista), pois (operador argumentativo explicativo) além de sua explicação clara, consegui ver exemplos práticos, diversas formas de aplicação, muitos sites, que com base neles, consegui me preparar para a "Interview". (tipo de argumento de explicação)

A: "Vídeos e sites com exemplos de interviews ajudaram para estudar". (tipo de argumento de exemplo).

W: "Por conta da Covid-19 não tivemos tantos exemplos em classe, o que poderia ajudar mais. Mas, foi algo totalmente inesperado para todos." (tipo de argumento de adversativa.)
\end{abstract}

Nesta primeira questão, a aluna G. relaciona os artefatos à compreensão de como atuar na AS: "interview", o que pode ser visto pelo trecho: "como fazer e nos comportar nessas ocasiões". A aluna M. comenta que achou o material relevante e sustenta seu ponto de vista com o tipo de argumento de explicação: "pois além de sua explicação clara, consegui ver exemplos práticos, diversas formas de aplicação, muitos sites, que com base neles, consegui me preparar para a "Interview" demarcado pelo operador argumentativo "pois", caracterizando a explicação pela conjunção. Na sequência, o aluno A. elabora um tipo de argumento de exemplo: "Vídeos e sites com exemplos de interviews ajudaram para estudar". Por último, em: "Por conta da Covid-19 não tivemos tantos exemplos em classe, o que poderia ajudar mais. Mas, foi algo totalmente inesperado para todos.", o aluno W. enuncia um ponto de vista com uma locução conjuncional subordinativa causal "por conta de" acompanhado por um tipo de argumento de adversativa demarcado pela conjunção "mas", lamentando que foram poucos exemplos na sala de aula em modalidade presencial e mostrando sua percepção sobre a ruptura do processo ocasionada pela doença.

Sabe-se que, em uma proposta de ensinoaprendizagem por meio de AS, os artefatos definemse como meios de modificar a natureza para alcançar o objeto idealizado e que podem ser manejados pelo sujeito na atividade na condução à determinada decisão e que, segundo Newman e Holzman (1993/2002), orientam o alcance no processo da 
atividade como instrumento-e-resultado. Dessa forma, diante os comentários dos alunos, constata-se que, de alguma forma, os artefatos oferecidos pela professora-pesquisadora pela plataforma virtual desempenharam papel importante para a manutenção e o alcance da atividade.

$\mathrm{Na}$ segunda questão, em relação às conversas, orientações e acompanhamento das tarefas (leitura e correção dos résumés e cover letters em língua inglesa antes da interview) por meio da plataforma virtual "Zoom.us", com a professorapesquisadora, $60 \%$ dos alunos responderam que acharam excelente e que colaboraram para sua participação na 'interview', 28\% acharam boa, enquanto $12 \%$ acharam satisfatório (pergunta 2).

Constata-se, por esses percentuais, que a professora-pesquisadora poderia ter propiciado um acompanhamento mais amplo ou ter experimentado diferentes ferramentas virtuais. Sobre essa mesma questão, tem-se os seguintes comentários:

E: "Nos deu dicas de como poderíamos melhorar e do que não fazer, achei ótimo" (ponto de vista).

$\mathrm{R}$ : "Para dar aula acredito que para disciplina Inglês, uma das plataformas para melhor interação do professor e Aluno recomendo Discord ou Microsoft Teams (ponto de vista) pois consegue ser mais dinâmico". (tipo de argumento de explicação)

O comentário do aluno E. demonstra seu ponto de vista acerca das intervenções da professorapesquisadora: "Nos deu dicas de como poderíamos melhorar e do que não fazer," que, de certa forma, se relaciona a um encorajamento para que o aluno alcance os objetivos para a proposta por meio de AS: "interview". O aluno R. enuncia seu ponto de vista em relação às plataformas virtuais e recomenda o uso de outras que, em sua opinião, são mais eficazes para as aulas de língua inglesa seguido por um tipo de argumento de explicação: “... uma das plataformas para melhor interação do professor e Aluno recomendo Discord ou Microsoft Teams pois consegue ser mais dinâmico". A explicação do aluno R. revela sua opinião sobre como seria uma melhor interação na modalidade virtual nas aulas.
O comentário do aluno R. também aponta a pouca experiência da professora-pesquisadora em relação às ferramentas virtuais, o que conduz à reflexão de que ela poderia experimentar outras formas para promover a interação e o dinamismo nas aulas em modalidade virtual.

Acima de tudo, essa fala do aluno $R$. demonstra aspectos emocionais sendo externalizados e compartilhados, que também aparecem em comentários de outros alunos, como será discutido em breve nesta análise.

Quando questionados sobre como se sentiram ao participar nesta proposta por meio da AS: "interview", levando em consideração que já conheciam a professora-pesquisadora e que tiveram várias etapas preparatórias (résumé e cover letter) e conversas sobre a importância de brincar/ performar, $52 \%$ dizem que se sentiram muito seguros, $32 \%$ sentiram-se bem, $8 \%$ médio e $8 \%$ inseguros (pergunta 3). Seguem os comentários sobre essa questão:

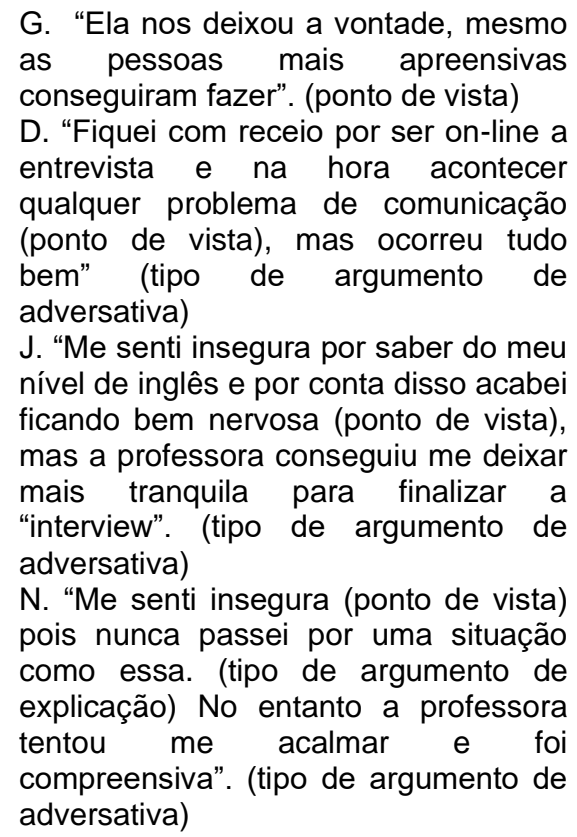

A aluna G. coloca seu ponto de vista: "Ela nos deixou a vontade, mesmo as pessoas mais apreensivas conseguiram fazer" que aborda o fato de os alunos estarem apreensivos para concluir a tarefa. $\mathrm{Na}$ mesma direção, a aluna D. expõe seu ponto de vista: "Fiquei com receio por ser on-line a entrevista e na hora acontecer qualquer problema de comunicação," que aponta uma insegurança marcada 
pelas escolhas lexicais "receio", "problema", seguida por um tipo de argumento de adversativa: “... mas ocorreu tudo bem", materializado linguisticamente pela conjunção adversativa "mas", confluindo para a ideia de que tudo acabou de acordo com o planejado.

A mesma construção argumentativa, pautada em apresentação do ponto de vista e seguida por tipo de argumento de adversativa denotando insegurança para se realizar a entrevista em língua inglesa, ocorre no comentário da aluna J., ao dizer: "Me senti insegura por saber do meu nível de inglês e por conta disso acabei ficando bem nervosa, mas a professora conseguiu me deixar mais tranquila para finalizar a "interview", utilizando as escolhas lexicais: "insegura", "nervosa", "tranquila".

Por último, ainda sobre a terceira questão do questionário, a aluna N. comenta: "Me senti insegura pois nunca passei por uma situação como essa." mostrando seu ponto de vista sustentado por um tipo de argumento de explicação marcado pela conjunção explicativa "pois". E, finaliza com o tipo de argumento de adversativa: "No entanto a professora tentou me acalmar e foi compreensiva". Essa elaboração também tem traços de insegurança demarcados linguisticamente por palavras como "insegura", "acalmar" e "compreensiva".

Na maior parte dos comentários dos alunos, mesmo nas questões anteriores, constata-se o estado emocional incidindo no discurso, que é importante em um processo em que envolve ensino-aprendizagem, desenvolvimento, recombinação do que se fazia, pois poderá orientar a produção de um novo modo de se realizar as aulas de língua inglesa. Retomando Moran e John-Steiner (2003), as emoções compartilhadas na atividade, a produção de sentidos e a própria experiência podem proporcionar comprometimento, vontade e personalidade criativa. Dessa forma, na formulação e compartilhamento dos comentários permeados por insegurança, os alunos têm a oportunidade de externalizar seus sentimentos, de refletir sobre suas participações, produzindo sentidos sobre seus processos de aprendizagem em tempo de pandemia. Já, a professora-pesquisadora possui a possibilidade de repensar seus encaminhamentos e propor mudanças. Portanto, esses compartilhamentos podem colaborar para o envolvimento de todos na atividade e permitir que cheguem a um produto novo de forma coletiva.

A quarta questão verifica o percentual de alunos que já participaram de uma entrevista em inglês, sendo que $40 \%$ dos alunos responderam que sim e um pouco mais da metade, $60 \%$ disseram não ter participado (pergunta 4). Para essa questão, não houve comentários.

Nesta quarta questão, os dados apontam a relevância na escolha da proposta de ensinoaprendizagem por meio da AS: "interview" e o papel do brincar/performance, uma vez que esses alunos se encontram cursando o quinto período de oito totais e precisam se preparar para participação ampla de suas vidas profissionais.

Revisitando Liberali (2009), sabe-se que o brincar proporciona experiências que vão além das possibilidades imediatas e contribui para que os alunos percebam outras formas de atuação no mundo por meio da imaginação. Portanto, neste estudo, o ensino-aprendizagem por meio de AS vinculado ao brincar/performance apresenta-se como possibilidade de se enfrentar o momento de pandemia, visando o desenvolvimento dos alunos.

$\mathrm{Na}$ sequência, a quinta questão aborda o quanto esta tarefa de "interview", em modalidade virtual nas aulas de língua inglesa na universidade, colaborou para o aluno ser avaliado em momento de pandemia, com distanciamento social. Os dados mostram que $60 \%$ considerou que a tarefa havia avaliado de forma excelente, $30 \%$ de forma boa e $10 \%$ satisfatória. (pergunta 5).

Para essa quinta questão, os alunos não teceram comentários. Mas, pode-se observar pelos percentuais que, mais uma vez, os alunos reconhecem o papel do brincar/performance para que conseguissem cumprir as exigências acadêmicas em tempo de pandemia, mesmo enfrentando dificuldades e restrições que surgiram no percurso, como problemas com a conexão de internet e dispositivos não compatíveis, nesse período de reinvenção. 
Por último no questionário respondido pelos alunos, a sexta questão versa sobre o aluno enxergar que esta simulação de 'interview' o/a ajudará quando estiver sendo entrevistado na vida real/profissional. Entre os dados dessa sexta questão, tem-se que $84 \%$ enxergam que a atividade "interview" em inglês o/a ajudará futuramente em que estiver sendo entrevistado na vida real/profissional de forma excelente. E, 16\% enxergam que ajudará de forma boa. (pergunta 6).

Ainda nesta sexta questão, os alunos teceram os seguintes comentários:

G: "Temos a realidade de entrevistas na língua que colocamos em nossos currículos, e esta atividade nos mostrou como nos preparar mais." (ponto de vista)

B: "A nos preparar para fazer um bom currículo em inglês e típicas perguntas e conversas que podem ocorrer em uma entrevista." (tipo de argumento de ilustração)

I: "Isso me ajuda a ter uma noção de como é uma entrevista em inglês."(ponto de vista)

Interligando esses comentários aos percentuais (84\% - excelente; $16 \%$ boa), observa-se que os alunos conseguem visualizar que a brincadeira/performance "interview" como AS na proposta de ensino-aprendizagem os coloca em contato com a atividade prática da esfera profissional. Isso é linguisticamente materializado nos comentários dos alunos como: "Temos a realidade de entrevistas na língua que colocamos em nossos currículos, e esta atividade nos mostrou como nos preparar mais." e "Isso me ajuda a ter uma noção de como é uma entrevista em inglês". Ainda, a aluna B. sustenta seu ponto de vista com o tipo de argumento de ilustração: "A nos preparar para fazer um bom currículo em inglês e típicas perguntas e conversas que podem ocorrer em uma entrevista".

Essa questão configura-se importante para, mais uma vez, se pensar o papel do brincar/performance. Retomando Holzman (2009), pelo brincar, criam-se situações que expressam desejos, pensamentos e ambições que ainda estão no plano imaginário. Por meio de performances de situações sociais, proporciona-se um momento de reflexão ao aluno; assim, a partir dela, permite-se ao aluno de Comércio Exterior que planeje sua atuação, antecipe reações e comportamentos que precisará apresentar para uma participação ampla na vida profissional futura.

Finalmente, constata-se 0 papel da transposição didática em perspectiva sócio-históricocultural em momento de pandemia. Revisitando Sánchez-Vázquez (2011), entende-se que a práxis criadora permite enfrentar novas necessidades e novas situações e que assim surgem as novas criações. Portanto, pode-se dizer que a proposta de ensino-aprendizagem de língua inglesa por meio da Atividade Social: "interview" configura-se como uma transposição didática com indícios de atividade criadora por apresentar recombinações, possibilitar o desenvolvimento dos alunos e criar algo novo em momento de pandemia.

\section{Considerações finais}

Este artigo objetivou relatar a experiência de uma professora-pesquisadora nas aulas de língua inglesa na universidade com transposição didática em momento de pandemia. Adotou como metodologia a pesquisa qualitativa com ênfase no paradigma crítico e analisou um questionário com seis perguntas respondidas e comentadas pelos alunos de quinto semestre do curso de graduação de Comércio Exterior em que a professora-pesquisadora leciona.

A problematização contextualizou a necessidade de se pensar uma alternativa nas aulas de língua inglesa em momento de pandemia. Nesse contexto permeado por inseguranças, dificuldades e preocupação de se promover o ensino-aprendizagem e formação aos alunos, a transposição didática surgiu como oportunidade para a manutenção das atividades e alcance dos objetivos, agora em modalidade virtual.

Fundamentada em uma perspectiva sóciohistórico-cultural, descreveu-se a proposta de ensinoaprendizagem por meio da Atividade Social: "interview". Além disso, elegeu-se o brincar/performance como a base para se pensar a 
realidade em vias de desenvolvimento, por promover a reflexão e a compreensão da realidade dos alunos para que possam problematizá-las e transformá-las de forma crítica.

Pela análise de dados, constatou-se que o brincar/performance "interview" exerce importante papel na atividade por proporcionar experiências que vão além das possibilidades imediatas do tempo de pandemia e contribui para que os alunos percebam, mesmo que incipientemente, formas de atuação no mundo (LIBERALI, 2009); assim, potencializa o desenvolvimento da atividade criadora.

Outra questão apontada pelos dados foi 0 estado emocional incidindo no discurso dos alunos, suas inseguranças e externalização de sentimentos que se integraram ao trabalho da professorapesquisadora, apresentando-se, segundo a visão das neovygotskyanas, Moran e John-Steiner (2003), como uma produção de sentidos essencial para que, professora-pesquisadora e alunos, criassem algo novo.

No geral, os dados mostraram a tentativa de se realizar uma transposição didática que, em uma perspectiva sócio-histórico-cultural, pode ser compreendida como uma atividade. Conforme Leontiev (1977), essa atividade surge de uma necessidade (no caso deste estudo, ligado à manutenção das aulas de língua inglesa), orienta o sujeito no mundo dos objetos (neste estudo, focado na formação acadêmica e profissional dos alunos), por meio de instrumentos (aqui os instrumentos estão ligados aos gêneros como cover letter, résumé e a própria "interview" que se apresentaram como instrumento-e-resultado, segundo Newman e Holzman (1993/2002).

Ainda, deve-se ressaltar que essas recombinações da professora-pesquisadora, mesmo que sucintas e permeadas por dificuldades, em não ter promovido a interação esperada pelos alunos, nem utilizado as plataformas virtuais preferidas por eles, configuram-se como uma transposição didática com indícios de atividade criadora, pois criam algo novo, por meio da brincadeira/performance inserida na proposta de ensino-aprendizagem com a AS: "interview"; despertam a imaginação e a fantasia, colaborando para desenvolvimento do aluno e seu futuro em momento de pandemia.

Finalmente, este relato de experiência permite refletir-se sobre a aprendizagem que se alcançou de, dentro de uma perspectiva sócio-histórico-cultural, encontrar alternativas em momento de dificuldades, como este momento de pandemia. Com base neste relato, ainda se pode arriscar em dizer que, essas apropriações, possivelmente, demarcarão uma mudança de paradigma no âmbito de ensino de línguas pós-pandemia, no Brasil e no mundo.

\section{REFERÊNCIAS}

BAKHTIN, Mikhail Mikhailovitch; VOLONOCHINOV. Marxismo e filosofia da linguagem: problemas fundamentais do método sociológico na ciência da linguagem. Tradução Michel Lahud e Yara Frateschi Vieira. 14 ed. São Paulo: Hucitec, 2010 [1929].

BAKHTIN, Mikhail Mikhailovitch. Os gêneros do discurso (1952-1953). In: Estética da criação verbal. Trad. Maria Ermantina Galvão G. Pereira. São Paulo: Martins Fontes, [1959-1961] 1997, p. 279-327.

CHEVALLARD, Yves; JOHSUA, Marie-Alberte. La transposition didactique: du savoir savant au savoir enseigné. Grenoble: Pensée Sauvage, 1985.

DELBONI, Beatriz Oliveira; VENDRAMINIZANELLA, Daniela Aparecida. O brincar e a atividade no ensino-aprendizagem de língua inglesa em relato de experiência na formação docente. Revista $X$, Curitiba, v. 14, n. 6, p. 255-271, dez. 2019.

DOLZ, Joaquim; SCHNEUWLY, Bernard. Gêneros e progressão em expressão oral e escritaelementos para reflexões sobre uma experiência suíça (francófona). In: DOLZ, Joaquim; SCHNEUWLY, Bernard. Gêneros orais e escritos na escola. Campinas: Mercado de Letras, 2004. 240 p. p. 41-70.

ENGESTRÖM, Yrjö. Activity Theory and individual and social transformation. In: Perspective on Activity Theory. Cambridge: Cambridge University Press, v. 19, n. 38, p. 19-30, 1999. 
FREIRE, Paulo. Pedagogia do oprimido. 17aㅗ ed. Rio de Janeiro: Paz e Terra, 1987. 184 p.

FREITAS, André Ricardo Ribas; NAPIMOGA, Marcelo; DONALISIO, Maria Rita. Análise da gravidade da pandemia de Covid-19. Epidemiologia e Serviços de Saúde, v. 29, p. e2020119, 2020.

GARONCE, Francisco; SANTOS, Gilberto Lacerda. Transposição midiática: da sala de aula convencional para a presencial conectada. Educação \& Sociedade, v. 33, n. 121, p. 1003-1017, out/dez. 2012.

GIROUX, Henry A. Cruzando as fronteiras do discurso educacional: novas políticas em educação. Porto Alegre: Artes Médicas, 1999. 298 p.

GOMES, Luiz Fernando. Inglês Instrumental para Comércio Exterior: proposta para um curso universitário. 1988. Dissertação (Mestrado em Linguística Aplicada e Estudos da Linguagem). Programa de Estudos Pós-graduados em Linguística Aplicada e Estudos da Linguagem, Pontifícia Universidade Católica de São Paulo, São Paulo, 1988.

HOLZMAN, Louis. Vygotsky at work and play. New York: Routledge, 2009. 168 p.

LEFFA, Vilson. Ilusão, aquisição ou participação. In: LIMA, Diógenes Cândido. Inglês em escola pública não funciona: uma questão, múltiplos olhares. São Paulo: Parábola Editorial, p. 15-32, 2011.

LEONTIEV, Alexei. Activity, consciousness and personality. Englewood Cliffs, NJ: Prentice Hall, 1977/ 2003.

LIBERALI, Fernanda Coelho. Atividade social nas aulas de língua estrangeira. São Paulo: Moderna, v. 01, 2009.

Argumentação em contexto escolar.

Campinas, SP: Pontes Editores, 2013.

LIMA, Maria Socorro Lucena. Reflexões sobre o estágio supervisionado na formação de professores. Revista Diálogo Educacional, Curitiba-PR, v. 8, n. 23, p. 195-205, jan. abril 2008.
MARX, Karl; ENGELS, Friedrich. A ideologia alemã, Teses sobre Feuerbach. São Paulo: Centauro,1845-46/ 2006.

MINAYO. Maria Cecília de Souza. (Org.) Pesquisa social: teoria, método e criatividade. Petrópolis: Vozes. 1993.

MORAN, Seana; JOHN-STEINER, Vera. Creativity in the Making: Vygotsky's Contemporary Contribution to the Dialectic of Development and Creativity. In: SAWYER, R. K. JOHN-STEINER, V.; MORAN, S.; STERNBERG, R. J.; FELDMAN, D. H.; NAKAMURA, J.; CSIKSZENTMIHALYI, M. Creativity and Development. New York: Oxford University Press, 2003, p.61-89.

NETTO, João Paulo. O que é marxismo. Brasiliense, 2017.

NEWMAN, Fred; HOLZMAN, Louis. Lev Vygotsky: cientista revolucionário. Tradução Marcos Bagno. São Paulo: Edições Loyola, 1993/ 2002.

PERELMAN, Chaïm; OLBRECHTS-TYTECA, Lucie. Tratado da argumentação: a Nova Retórica. 6. ed. São Paulo: Martins Fontes, 1958/2005

PHILIPPOV, Renata; LIBERALI, Fernanda Coelho. A experiência com gestão da escrita do gênero resumo de obra literária na disciplina de literatura inglesa em currículo de letras: pensando a desencapsulação. In: PHILIPPOV, Renata; SCHETTINI, Rosemary Hohlwnwerger; SILVA, Kleber Aparecido. (Org.). Integrando e Desencapsulando Currículos do Ensino Superior, Campinas: Pontes Editores, 2015, p. 71-96.

SANCHEZ-VAZQUEZ, Adolfo. Filosofia da práxis. 2. ${ }^{\text {a }}$ ed. São Paulo: Expressão Popular, Brasil, 2011.

VENDRAMINI ZANELLA, Daniela Aparecida. Reprodução de orientações na constituição das atividades de formação docente em cadeia criativa". In: LIBERALI, Fernanda Coelho; FUGA, Valdite Pereira. (Orgs.) Cadeia Criativa: teoria e prática em discussão. Campinas, SP: Pontes. pp. 187- 213, 2018.

Por uma formação crítico-criativa de alunas-professoras e professora-pesquisadora na graduação em Letras. Tese (Doutorado em 
Linguística Aplicada e Estudos da Linguagem) Pontifícia Universidade Católica de São Paulo, 2013. e LIBERALI, Fernanda Coelho. Brincar no hospital: uma produção criativa na formação de alunos-educadores. Linguagem \& Ensino, Pelotas, Vol. 1, No. 14, 11. jan./jul. 2011.

VYGOTSKY, L. S. A construção do pensamento e da linguagem. São Paulo: Martins Fontes, 1934/ 2001.

$$
\text { Imaginação e Criação na }
$$

Infância. Ana Luiza Smolka comenta. Tradução Zoia. Prestes. São Paulo: Editora Ática, 1930/ 2009.

\section{AGRADECIMENTOS}

Agradecemos ao Conselho Nacional de Desenvolvimento Científico e Tecnológico (CNPq) pela bolsa que foi financiada para o desenvolvimento do presente estudo.

VENDRAMINI-ZANELLA, Daniela Aparecida; DELBONI, Beatriz Oliveira. Atividade criadora em momento de pandemia: relato de experiência das aulas de língua inglesa. Signo, Santa Cruz do Sul, v. 46, n. 85, p. 248-261, jan. 2021. ISSN 1982-2014. Disponível em: <https://online.unisc.br/seer/index.php/signo/article/view/15657>. doi:https://doi.org/10.17058/signo.v46i85.15657. 